\title{
Multidisciplinary Vertically Integrated Project (VIP) Teams at the University of Hawaii: Challenges and Synergy
}

\section{Dr. A Zachary Trimble, University of Hawaii at Manoa}

A Zachary Trimble is an Assistant Professor of Mechanical Engineering and self described Gizmologist. Zac received his bachelor's from the University of Utah and both his Masters' and PhD from Massachusetts Institute of Technology (MIT) for his work on Vibration Energy Harvesting. Currently Zac is pursuing research in precision astronomical instruments, Anisotropy in 3D printing, Frequency Tuning of Vibration Energy Harvesters, automating climate change studies, and autonomous systems.

\section{Dr. Wayne A. Shiroma, University of Hawaii at Manoa}

Wayne A. Shiroma received the B.S. degree from the University of Hawaii at Manoa, the M.Eng. degree from Cornell University, and the Ph.D. degree from the University of Colorado at Boulder, all in electrical engineering. In 1996, he joined the University of Hawaii at Manoa, where he is currently Professor and Chair of Electrical Engineering. He has authored or coauthored over 100 publications in the areas of phased arrays, spatial power combining, and nanosatellites. He was also a Member of the Technical Staff with Hughes Space and Communications, El Segundo, CA. Dr. Shiroma was the recipient of the the 2015 UH Peter V. Garrod Outstanding Graduate Mentoring Award and the 2003 UH Regents Medal for Excellence in Teaching, the ten-campus UH System's most prestigious teaching award. Since 2001, IEEE-HKN, the international honor society for IEEE, recognized four of his graduating seniors as the most outstanding electrical engineering students in the U.S.

\section{Dr. David Garmire, University of Hawaii at Manoa}

David Garmire received B.S. degrees at Carnegie Mellon University, and the Ph.D. at UC Berkeley in 2007 with a certificate in Management of Technology from the Haas School of Business. He won the 2008 Ross N Tucker Award for advancing semiconductor technology and the 2007 Sevin Rosen Funds Award for Innovation. He is currently an Associate Professor in the department of Electrical Engineering at the University of Hawaii at Manoa, where he develops microsensors, microactuators, and technologies for rapid prototyping, visualization, renewable energies and sustainability.

\section{Dr. Aaron T. Ohta, University of Hawaii at Manoa}

Dr. Aaron Ohta received a B.S. from the University of Hawaii at Manoa in 2003, an M.S. from the University of California, Los Angeles in 2004, and a Ph.D. from the University of California, Berkeley in 2008, all in the field of electrical engineering. He is currently an Associate Professor of Electrical Engineering at the University of Hawaii at Manoa, where he has been since 2009. Dr. Ohta's research interests include microelectromechanical systems (MEMS) and microfluidics. He has published two book chapters and over 100 peer-reviewed journal and conference papers, and is co-inventor on three U.S. patents. 


\title{
Multidisciplinary Vertically Integrated Project (VIP) Teams at the University of Hawai' $i$ : Challenges and Synergy
}

\begin{abstract}
The Vertically Integrated Projects (VIP) Program is characterized by large, multidisciplinary teams of undergraduate and graduate students focused on long-term research problems aligned with the faculty mentor's field of interest. In terms of methodology, it follows a project-based cohort approach to education where students can potentially work on the same project over multiple years and with a familiar group of students. One of the challenges in running a VIP team is the multidisciplinary aspect. This paper discusses the challenges associated with transitioning traditionally discipline-siloed projects to multidisciplinary projects using VIP as the catalyst. Said another way, we describe the ongoing lessons learned of changing the mindset of students (and faculty) from "you're electrical engineering, I'm mechanical engineering" to "we're engineering".
\end{abstract}

In Fall 2015, the VIP Program at the University of Hawai 'i consisted of six VIP teams: three composed primarily of EE students, one composed of ME students, and two with a mix of engineering students. The latter two teams are used as case studies to test our theories for incorporating multidisciplinary VIP teams into existing curricula. A desired outcome of this investigation will be elucidating a best-practices approach for VIP teams across disciplines including electrical, computer, mechanical, and civil engineering. This includes how to initiate formation of such groups, how to handle curriculum challenges between the programs, and how to handle the needs of the students within this educational program. Ultimately, we hope to develop learning in a multidisciplinary design environment that also fulfills the requirements of a degree in engineering, to the benefit of all the students involved, regardless of major.

\section{Introduction and Motivation}

Project-oriented learning is already well established as an invaluable part of an engineering education, ${ }^{1,2,3}$ Furthermore, industry professionals report improved results from students who participate in multidisciplinary projects. ${ }^{4,5,6,7,8}$ In fact, the engineering departments in this institution have a history of multidisciplinary projects. One of the largest multidisciplinary projects began 15 years ago, and involved 60 electrical and mechanical engineering students, and seven advisors from those departments. ${ }^{9,10}$ However, in this project and others, it became obvious that challenges existed because of the multidisciplinary nature of the teams. Analyzing these challenges is a key step to ensuring the long-term survival of multidisciplinary project teams.

Why should students participate in multidisciplinary projects? First, students often view hands-on projects as fun and exciting, allowing them to work on something they want to (the "hey, this is why I thought I wanted to be an engineer" factor). Second, it helps them apply the knowledge gained from lecture courses to a hands-on project. Third, working on multidisciplinary projects helps bolster their resumé, and provides them with a team-based experience that approximates the working environment in many engineering companies. ${ }^{6,5}$ Finally, working on multidisciplinary 
projects gives engineering students the opportunity to socialize in a relaxed, out-of-classroom setting.

Based on the evidence of the virtues of multidisciplinary projects in engineering education, several different pedagogies have emerged. ${ }^{11,12,13,14,15,16}$ One example that incorporates all the previously mentioned advantages to students is the Vertically Integrated Projects (VIP) Program. The VIP Program seeks to foster long-term, in-depth, project-based learning to engage students and better prepare them for future careers. ${ }^{17,13}$ True to its name, each VIP team is vertically integrated, consisting of one or more faculty mentors, graduate student researchers, and undergraduates from the freshman to senior levels. The teams are large (10 to 20 undergraduates per semester) and the long-term projects (at least 5 years) are based on an externally funded research topic that is aligned with the faculty mentor's field of interest. In terms of methodology, each VIP team follows a project-based cohort approach to education where students can work on the same project over multiple years with a familiar group of students.

Indeed, the only disadvantage to students participating in a multidisciplinary VIP project is the additional workload in an already overwhelming curriculum. But if this is the only disadvantage, then it seems obvious that departments should want to provide appropriate credit toward a degree.

This paper discusses the challenges associated with transitioning traditionally discipline-siloed projects to multidisciplinary projects using VIP as the catalyst. Said another way, we describe the ongoing lessons learned, from two slightly different perspectives, of changing the mindset of students (and faculty) from "you're electrical engineering, I'm mechanical engineering" to "we're engineering."

Primarily, two parallel case studies are presented for comparison: 1 - Hyperboreans; A multidisciplinary team which has an accepted entry into the Hyperloop Challenge, and consists of students from civil (1), computer (1), electrical (2), and mechanical (3) engineering. The majority of the students are participating because they are passionate about the project and only expect academic compensation in the form of additional credits that show up as invaluable experience on a transcript and resume, but do not count directly toward a degree. 2 - University of Hawai'i $\mathbf{i}$ Drone Technology (UHDT); A VIP project involving 23 students: computer (3), electrical (6), mechanical (11), and pre-engineering (3) students, spanning the freshman (3), sophomore (9), junior (4), and senior (7) levels. This VIP team tackled a naturally multidisciplinary project: design, build, and fly a drone for a national competition. The majority of the students participating in this team are receiving credit toward their respective degrees.

\section{Challenges with multidisciplinary teams}

Based on our experience, the challenges in mentoring multidisciplinary projects are not primarily (or even secondarily) pedagogical. In our experience, the true challenge for multidisciplinary projects is logistical. In a nutshell, the ultimate challenge is this: How do faculty break down the rigid, traditional, discipline-siloed curricular programs and transition them to a more multidisciplinary approach?

From the 10,000-foot view, the fact that our grand challenge is logistical rather than pedagogical is fortunate, since logistical challenges can often be overcome - well, in theory anyway. However, 
the devil is indeed in the details and these very logistical details are what causes frustration among students and faculty alike.

This paper focuses on two categories of challenges important when transitioning traditional discipline-siloed programs to a multidisciplinary environment: how to form and manage multidisciplinary groups, and how to handle curriculum issues between programs.

\section{Forming and managing multidisciplinary groups}

Hyperboreans Largely the problem of project formation and spreading the idea of the project to groups from across departments falls to the individual faculty members and students that are already a part of the team. To facilitate coordination, the faculty advisor implemented an open-source tool, MatchMaker, for connecting faculty and students to projects as well as creating new projects. While other tools exist for funding existing projects [experiment.com, kickstarter], few tools exist for creating optimal project teams in an academic setting. In such settings, we asked the question: "what are students really looking for?" Typically they are looking for other students with complementary or synergistic skill sets. The tool therefore allows students to write what skills they are looking to acquire as well as what skills they already have. The tool can then automatically suggest teams of students with which to connect together. By implementing a simple chat feature, students can then see if they are a good match and come up with project ideas for their newly formed teams. By scraping the school webpages for course data, students need only add a list of course registration numbers to their profile to obtain scheduling information. This additional information aids in project formation by eliminating logistical issues of forming a time for everyone to meet. While it was found that the tool helped, initial formation was more greatly aided by students bringing in their friends/colleagues from other departments or students they connected with during the semester. This process revealed the following keys to initiating a solid foundation in the formation of multidisciplinary groups:

- Students who join multidisciplinary groups have a weaker tie to the group and its successful outcome given the siloed nature of the undergraduate curriculum.

- Students have a stronger tie to the group if there is a non-scholastic attribute that connects them: they already socialize and hang out together outside of class or they have other common interests.

- While familiarity between students in the same discipline may breed contempt (perhaps due to competition), familiarity across disciplines appears to breed camaraderie and trust.

- Leadership is tricky in a multidisciplinary group because students of multiple disciplines know that the leader from another discipline does not have the domain expertise. As such, a committee leadership structure is required where each discipline has a leader. Among those discipline leaders a higher-level leader will generally arise simply to maintain the coordination and progress of the group. It still appears challenging how the advisor (typically from one discipline) can inject suggestions and guide the group.

UHDT The initial formation of UHDT was entirely student-initiated. A couple of EE students approached the team's advisor during the summer between their junior and senior year. Those 
juniors were already high school friends, and recruited a whole cadre of their own friends to form UHDT in Fall 2013; they selected quadrotor drones as their topic of choice primarily because drones started becoming all the rage around that time. In our experience, successful projects often have "friends working with friends" as a key ingredient. They hang out with each other scholastically in lecture classes, and socially in clubs such as IEEE and ASME, so it comes natural for them to hang out working on a project.

Offering the project for credit as part of an existing curriculum increases the advertising of the project to other engineering students, but puts the team dynamic at risk. When students who are not part of the group of friends join the project, communication and expectations must be more closely managed. As mentioned the initial group of friends communicate on a regular basis and share a passion for the project and thus drive each other to complete the project. However, when students join the project just for the academic design credit they do not have that same passion and drive. They often contribute less to the group either because they are disinterested and thus satisfied to do the minimum required, or more dangerously because they are not privy to the personal communication channels being used and thus are not included.

\section{Curriculum challenges}

Hyperboreans: It was interesting for this particular group to handle the curriculum challenges between the departments. Since the Hyperloop Pod has subsystems and components from every discipline, there was a natural split on how to handle and incorporating knowledge from each curriculum. There are subsystems on thermodynamics (ME), structural (CEE), aerodynamics (CEE/ME), levitation and magnetic propulsion (EE), and controls (CENG). It was interesting to see that students from other disciplines were interested in the cross-discipline challenges and actually picked up some of the concepts of their cousin departments.

Unfortunately, for obtaining course credit for this multidisciplinary team, students chose not to actively seek course credit, but rather joined the team for experience. There did not seem to be a mechanism that would help connect the student effort to their academic progress other than making respective faculty within their departments aware of their effort. Additionally, this group would have had the added challenge of coordinating course credit across four degrees. However, since the students are participating solely for extracurricular benefit and the course requirements are not prescribed by the department curriculum, the learning experience is better tailored to the students interests and needs.

Additional logistical problems arose pertaining to scheduling, how deadlines are arranged, and setting up priorities when students are not receiving credit that counts directly toward their degree. The student captain of the Hyperboreans team had to step down and let an EE student take over due to ME senior design work. If the Hyperboreans project could have counted for ME senior design, this would not have been an issue.

UHDT Short of solving the grand challenge of breaking down the rigid, traditional, discipline-siloed curricular programs and transitioning them to a more multidisciplinary approach just yet, we are currently working within the confines of siloed EE and ME curricular programs as shown in Fig. 1. Currently electrical and mechanical engineering students have identical general 
education, engineering sciences, and math requirements, and take introductory circuits and programming courses together. Subsequently, students are siloed into disciplines and have limited interaction, even though multidisciplinary learning and design experiences better prepare students for their future careers. A potential curriculum removes the silos of electrical and mechanical engineering and sets the VIP program as the central focus and the only "silo." In this case, all students take the discipline-relevant core courses in support of the project they are working on. The students interact as a cohort from start to finish - from general education and math to graduation. However, such an idealized plan is difficult to implement in the face of already established pedagogy.

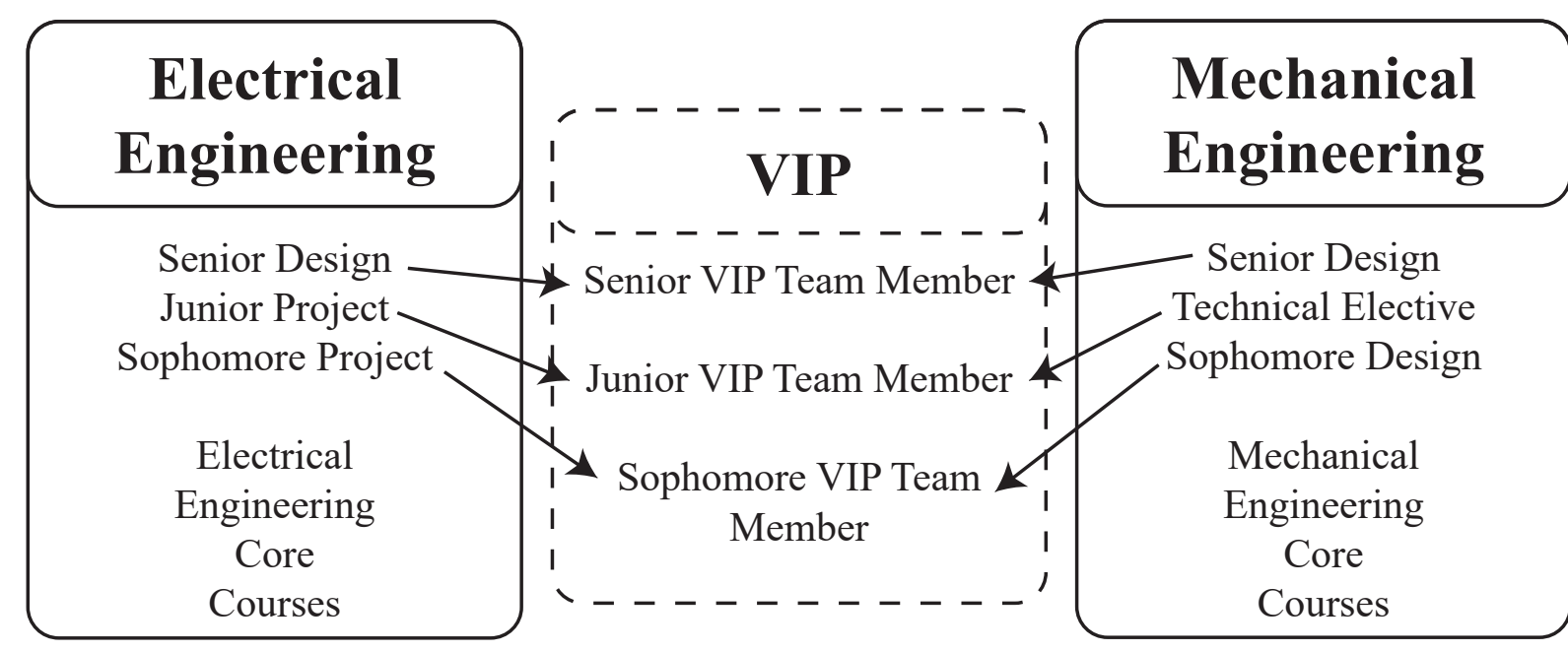

Overlapping Engineering Courses: Basic Circuits, Introductory Programming Engineering Mechanics

Math

Engineering Sciences: Physics, Chemisty

General Education: Arts, Humanities, English, Communication, etc.

Figure 1: Electrical and mechanical engineering students have identical general education, engineering sciences, and math requirements, and take introductory circuits, programming and mechanics courses together. Subsequently, students are siloed into disciplines and have limited interaction, even though multidisciplinary learning and design experiences better prepare students for their future careers. Substantially changing existing curricula across multiple departments is at minimum difficult and most likely will require on-site proof that such changes are a necessary course of action. Thus, the initial goal is to allow students to work on multidisciplinary VIP projects within the context of already established courses.

To approach the VIP-centered idea within the confines of already-established department curricula, the initial goal is to allow students to work on multidisciplinary VIP projects within the 
context of already established courses (Fig. 1). The case study presented here focuses on electrical and mechanical engineering which, as previously discussed, already have significant overlap and already include project-based courses. The electrical engineering department curriculum includes design experience courses sophomore through senior year that students can take for credit while working on the VIP project. The mechanical engineering department uses a technical elective for the junior VIP experience.

The challenges that have been encountered with this mapping are:

- ME seniors are enrolled in a senior design course (ME 481) taught by an ME professor, and all other EE and ME students are enrolled in EE project courses (EE 196, EE 296, EE 396) taught by an EE professor.

- ME and EE faculty mentors rarely had the same schedule to have weekly meetings together. Efforts were made to have a handful of times (mostly for reviews) where both could be in the same room at the same time for all 23 students.

- The ME sophomores enrolled in EE 296 receive academic credit for EE 296, but these credits do not count for their degrees. Without getting credit toward their degree, how can ME students be retained for their junior year? More generally, programs do not have a lot of wiggle room for more courses, so how do the projects count toward graduation?

To address the first challenge, the EE advisor adapted his syllabus milestones to coincide as closely as possible to those of the ME advisor's syllabus (within 90\% coincident). Even then, on cases where the exact instructions differed, there were complaints from the ME seniors about having to do "double work." Therefore in the final report, the EE syllabus was adjusted to adopt exactly the requirements set forth by the ME senior design professor. Incredibly, the EE freshmen ended up writing more words/student than the ME seniors. Even the sophomores and juniors ended up writing more words/student than the ME seniors. Likely this is another manifestation of the team-formation issues. Those team members that are participating in the project solely for credit and not for passion are almost entirely ME seniors. As such they are unhappy if there are any additional requirements placed upon them and happy to pass their work off if possible. The moral of the story, so far, is that for multiple faculty overseeing a project via different courses, the faculty should agree beforehand on common requirements.

The second challenge should also be addressed in the previously mentioned agreement between faculty. It is important for students to be presented with a common message from both faculty simultaneously.

The third challenge was caused by a logistical miscommunication between faculty members. Initially the faculty teaching the ME sophomore design course agreed to allow students to fulfill the project part of his course through the VIP team. However, when students enrolled in the course they were not allowed to work on a the VIP project but rather a "similar" project. In that faculty member's opinion, he was providing the knowledge, through work on the similar project, that would then be applied to the VIP project, but it was impossible for the VIP project to directly count as he did not have control or authority to assess the students' work on the VIP project. In the future an explicit written agreement is being drafted to ensure the requirements of the sophomore design course can be met and that the faculty in charge of the course is in a position to 
properly assess the student's learning rather than simply entrusting this to a professor from a different department.

\section{Conclusion (i.e. Best practices so far)}

First and foremost, in both case studies working on multidisciplinary teams was beneficial for the students. Assessment of this statement is currently mostly qualitative. Local industry professionals comment on the ambitious yet successful projects these programs undertake. Past students return to comment that these multidisciplinary projects better prepared them for their current jobs than any other courses. The students in these projects have a higher maturity level than their colleagues. When compared with other senior design students, their level of written and oral communication is higher, their ability to plan for and meet deadlines is better, the amount of direction they require during an open-ended design problem is less, and their overall quality of work is higher. The students in these project also have a deeper understanding of the core engineering subjects. For example, students on the UHDT team were seeing the value of and directly using the theory they were learning in their basic circuits course on a weekly basis. They were applying Ohm's law to the selection of motors and batteries, and they were applying the knowledge in the purview of a larger context that included other disciplines like heat transfer and aerodynamics. Another measure of maturity is expressed during design reviews where participating students have an enhanced ability to express their work in the context of the bigger picture, as it relates to achieving the overall mission (e.g. how is image processing tied to vibration which is tied to structural design and perturbations from the power system).

We have found that undergraduates - even at the freshman level - are excellent self-learners when they are self-motivated by a project. When faced with a technical problem involving material outside their normal curriculum, students simply surf the web to look up the information on their own, or seek out advice from other faculty or project mentors.

Both case study teams found that the learning needs of the students were relatively easily met through outside resources. The Hyper team is advised by an EE professor who found that as a single disciplined advisor, it was a challenge to handle the needs of all the students, but the advisor found as a best practice to have separate faculty experts from each of the departments come in as advisors to the group. This worked to an extent. Giving credit to faculty who are pop-up advisors is another challenge, but for the most part faculty are happy to provide their expertise. The UHDT team included an EE primary advisor and an ME secondary advisor which covered the general needs of each discipline, but local industry and enthusiast experts were also utilized for specific knowledge based needs.

A common observation over 15 years of project-based learning is that students who don't do well in the traditional classroom setting, on occasion, will excel in the project setting, especially if they are passionate about the project and delegated leadership roles. For example a 2.5-GPA student can often shine with a project, and have something very tangible to place on a resumé especially if that student is in a leadership position. ${ }^{18,19}$ For a larger groups $(>15)$, there will undoubtedly be those who contribute a lot to the project versus those that contribute little. It is the Paretto Principle, where $20 \%$ of the people do $80 \%$ of the work. To get the outliers to contribute, one successful practice has been to assign them to some type of leadership role.

Additional oversight and management of group dynamics by the advisor is necessary for teams 
formed as part of the existing curriculum. Teams need at least a significant core who are passionate about the project and would participate in the project regardless of course credit.

In programs with existing project courses it seems obvious that the VIP program should be an easy replacement. However, there are challenges getting departments to give up perceived power or control of content. For situations where participating professors are also active mentors the situation is somewhat easier but requires each professor to agree on a cohesive set of deadlines and requirements before the semester starts to ensure the team is working together toward a common goal rather than as disparate subsets. Even if only one professor manages the entire team common milestones are suggested. When disparate curricula and milestones are being satisfied simultaneously teams segment into subgroups associated with the course they are getting credit for. This natural segmentation becomes particularly pronounced if the requirements and deadlines do not match (i.e. if Student 1 has a report due on Friday that requires information from Student 2 , whose report is not due until the following week, then it become dangerous for Student 1 to rely on Student 2 for the information, as Student 2 has little personal motivation to deliver on time.) For situations where the participating professors are not also active mentors additional communication is key. Ensure agreements are worked out and mutually understood.

Our VIP programs are growing steadily each year (Hyperboreans had a 50\% return rate from the previous academic year and $80 \%$ growth, UHDT had a $43 \%$ student return rate from the previous year and is expected to have a $77 \%$ return rate next academic year, and the other VIP teams at University of Hawai ' $i$ are similarly expanding). Our VIP students seem happier with their choice to become engineers and are more engaged. Based on these results alone, the lessons learned above are well worth the effort to implement.

\section{References}

[1] Sivachandran Chandrasekaran, Alex Stojcevski, Guy Littlefair, and Matthew Joordens. Learning through projects in engineering education, 23 September 20122012.

[2] Magdalini Lagoudas and Jeffrey E Froyd. Aggie-challenge program: A multidisciplinary, vertically integrated, project-based engineering program. QScience Proceedings, page 73, 2015. ISSN 2226-9649.

[3] Stuart Palmer and Wayne Hall. An evaluation of a project-based learning initiative in engineering education. European Journal of Engineering Education, 36(5):357-365, 2011. doi: 10.1080/03043797.2011.593095.

[4] Robert H Todd, Carl D Sorensen, and Spencer P Magleby. Designing a senior capstone course to satisfy industrial customers. Journal of Engineering Education, 82(2):92-100, 1993. ISSN 2168-9830.

[5] Nathan Hotaling, Barbara Burks Fasse, Lewis F Bost, Christopher D Hermann, and Craig R Forest. A quantitative analysis of the effects of a multidisciplinary engineering capstone design course. Journal of Engineering Education, 101(4):630-656, 2012. ISSN 2168-9830.

[6] Maria Gorlatova, John Sarik, Peter Kinget, Ioannis Kymissis, and Gil Zussman. Project-based learning within a large-scale interdisciplinary research effort. In Proceedings of the 18th ACM conference on Innovation and technology in computer science education, pages 207-212. ACM, 2013. ISBN 1450320783.

[7] Karin Wolff and Kathy Luckett. Integrating multidisciplinary engineering knowledge. Teaching in Higher Education, 18(1):78-92, 2013. ISSN 1356-2517.

[8] Guy A Bingham, Darren J Southee, and Tom Page. Meeting the expectation of industry: an integrated approach for the teaching of mechanics and electronics to design students. European Journal of Engineering Education, 40(4):410-431, 2015. 
[9] Wayne A Shiroma, Aaron T Ohta, and Michael A Tamamoto. The University of Hawai 'i CubeSat: a Multidisciplinary Undergraduate Engineering Project. In Frontiers in Education, 2003. FIE 2003 33rd Annual, volume 3, pages S3A-7. IEEE, 2003.

[10] Wayne A Shiroma, Jason T Akagi, Aaron T Ohta, Justin M Akagi, and Byron L Wolfe. Small satellites for rapid-response communication and situational assessment. In Wireless Information Technology and Systems (ICWITS), 2012 IEEE International Conference on, pages 1-4. IEEE, 2012.

[11] Magdalina Z Lagoudas and Jeffrey E. Froyd. Multidisciplinary vertically integrated teamsworking on grand challenges, 2015.

[12] Ronald L. Miller and Barbara M. Olds. A model curriculum for a capstone course in multidisciplinary engineering design. Journal of Engineering Education, 83(4):311-316, 2013. ISSN 2168-9830. doi: 10.1002/j.2168-9830.1994.tb00124.x.

[13] Randal Abler, Edward Coyle, Rich DeMillo, Michael Hunter, and Emily Ivey. Team-Based Software/System Development in the Vertically-Integrated Projects (VIP) Program, pages 287-294. Springer, 2012. ISBN 3642259073.

[14] Sivachandran Chandrasekaran, Guy Littlefair, Matthew Joordens, and Alex Stojcevski. A comparative study of staff perspectives on design based learning in engineering education. Modern Educational Review, 4(3): 153-168, 2014. doi: 10.15641/jmer(2155-7993)/03.04.2014/001.

[15] Ronald L Miller and Barbara M Olds. A model curriculum for a capstone course in multidisciplinary engineering design. Journal of Engineering Education, 83(4):311-316, 1994. ISSN 2168-9830.

[16] David S Strong. An approach for improving design and innovation skills in engineering education: The multidisciplinary design stream. International Journal of Engineering Education, 28(2):339, 2012. ISSN 0949-149X.

[17] Randal Albler, Julia Melkers, Aaron Ault, Tamara Clegg, James Krogmeier, and Edward Coyle. Enabling and evaluating collaboration of distributed teams with high definition collaboration systems, 20 June 20102010.

[18] D. Southland. Hawaii, we have liftoff: students at uh manoa are preparing to launch the islands' first homegrown satellites into orbit. volume 16, pages 107-113. Hana Hou! The Magazine of Hawaiian Airlines.

[19] Wayne Shiroma, Justin Akagi, Byron Wolfe, Jason Akagi, Zachary Lee-Ho, and Aaron Ohta. Big potential for small-satellite students. pages SSC09-XII-7. Proceedings of the 23rd Annual AIAA/Utah State University Conference on Small Satellites, 2009. 